\title{
RELIABILITY OF WIND SPEED DATA FROM SATELLITE ALTIMETER TO SUPPORT WIND TURBINE ENERGY
}

\author{
M. N. Uti ${ }^{\mathrm{a}}$, A. H. M. Din ${ }^{\mathrm{a}, \mathrm{b}, \mathrm{c}}$, and A. H. Omar ${ }^{\mathrm{a}}$ \\ ${ }^{a}$ Geomatic Innovation Research Group (GIG) \\ ${ }^{\mathrm{b}}$ Geoscience and Digital Earth Centre (INSTEG), Faculty of Geoinformation and Real Estate, Universiti Teknologi \\ Malaysia, 81310 Johor Bahru, Johor, Malaysia \\ ${ }^{c}$ Associate Fellow, Institute of Oceanography and Environment (INOS), Universiti Malaysia Terengganu, Kuala \\ Terengganu, Terengganu, Malaysia, Email: amihassan@utm.my
}

KEY WORDS: Wind Speed Data, Wind Turbine Energy, Satellite Altimeter, Radar Altimeter Database System, Ground-truth buoy

\begin{abstract}
:
Satellite altimeter has proven itself to be one of the important tool to provide good quality information in oceanographic study. Nowadays, most countries in the world have begun in implementation the wind energy as one of their renewable energy for electric power generation. Many wind speed studies conducted in Malaysia using conventional method and scientific technique such as anemometer and volunteer observing ships (VOS) in order to obtain the wind speed data to support the development of renewable energy. However, there are some limitations regarding to this conventional method such as less coverage for both spatial and temporal and less continuity in data sharing by VOS members. Thus, the aim of this research is to determine the reliability of wind speed data by using multi-mission satellite altimeter to support wind energy potential in Malaysia seas. Therefore, the wind speed data are derived from nine types of satellite altimeter starting from year 1993 until 2016. Then, to validate the reliability of wind speed data from satellite altimeter, a comparison of wind speed data form ground-truth buoy that located at Sabah and Sarawak is conducted. The validation is carried out in terms of the correlation, the root mean square error (RMSE) calculation and satellite track analysis. As a result, both techniques showing a good correlation with value positive 0.7976 and 0.6148 for point located at Sabah and Sarawak Sea, respectively. It can be concluded that a step towards the reliability of wind speed data by using multi-mission satellite altimeter can be achieved to support renewable energy.
\end{abstract}

\section{INTRODUCTION}

\subsection{Research Background}

Malaysia has attempted to implement wind energy as one of the renewable energy (RE) source to accommodate the electrical power in Malaysia. Thus, many research and studies have been conducted by professionals and government agencies such as Malaysian Meteorological Department (MMD). Unfortunately, the study of wind speed for both onshore and offshores in Malaysia was deadlocked due to the location and method used (L. W. Ho, 1993). The geographical location of Malaysia at low wind-speed region has brought difficulties in wind speed study. Most of the research locations were placed at meteorological stations which are near/at airport and it is not suitable placed for wind speed study due to bias of wind speed observation caused by airplanes (L. W. Ho, 1993).

Besides that, MMD had conducting wind speed study at offshore areas by deployment of buoy and Volunteer Observing Ships (VOS). But, due to the shortage in data distribution by VOS members brought a great challenge to assess the wind speed data (L. W. Ho, 1993). Other than that, the existence of strong wind at a distinct time and location (low temporal and limited spatial coverage) becomes the biased factors of analysing the wind speed data by using buoy and VOS. Most of the wind speed observations conducted using the in-situ platforms such as ships and buoys have limited in spatial coverage and temporal. Since there are limitations for in-situ wind speed observation techniques in Malaysia to support the renewable energy thus, the aim of this research is to study the reliability of wind speed data using multi-mission satellite altimeter to support wind turbine generator over Malaysian seas. Thus, the scope of this research covers a 24 years (1993-2016) of wind speed data from satellite altimeter and moored buoy. Wind speed data from satellite altimeter are retrieved by using Radar Altimeter Database System (RADS). The first point of buoy is located at Sarawak offshore $(5.15 \mathrm{~N}, 111.82 \mathrm{E})$ and the second point is located at Sabah Sea $(5.83 \mathrm{~N}, 114.39 \mathrm{E})$. For altimeter wind speed data retrieval are covered from $0^{\circ}$ to $14^{\circ}$ of latitude and $95^{\circ}$ to $125^{\circ}$ of longitude including Malaysian Seas such as Malacca Straits, South China Sea, Celebes Sea and Sulu Sea, as shown in Figure 1. After that, data verification is conducted by comparing both of wind speed observation from satellite altimeter and buoy. Moored buoy will be acted as a ground-truth or bench-mark since it was point-based observation data. Verification of these data is focusing on the accuracy of the satellite altimeter measurements and its significance to provide a reliable data in terms of good spatial and temporal. These verification part also accounted with statistical analysis such as time-series graph, correlation and root mean square error (RMSE). Besides that, an assessment of the wind speed with respect to seasonal effect is approached by conducting an altimeter wind speed climatology data over 24 years from 1993 until 2016. The seasonal effect includes 
Northeast Monsoon (November to February), Southwest Monsoon (May to August), First Inter-Monsoon (March and April) and Second Inter- Monsoon (September and October). The significant of this assessment is to identify and propose a potential location at/near offshores that received high wind speed for the wind turbine generator.

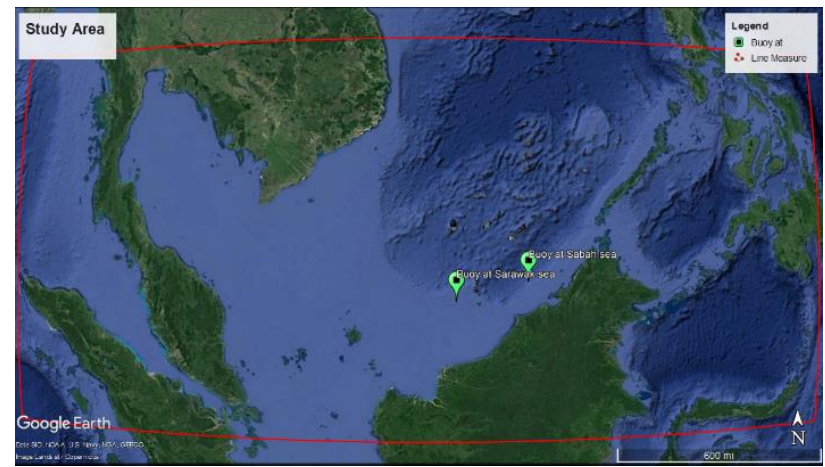

Figure 1. The map of study area (NOAA, 2010).

\subsection{Satellite Altimetry Concepts}

The basic principle of satellite altimeter is referred to the reflected pulse from the surface and backscattered of the wind and waves. Then, the pulse is received by altimeter sensor in a few milliseconds. There are several parameters for satellite altimeters which are returned signal from the sea; slant of the reflected signal; distance, $d$ from the sea level (measured by the time travel of the pulse); wind speed determination by the power from the impulse response. (Abdul Aziz et al., 2014)).

Since this technique acquired some parameters for calculation that mentioned above, several corrections for altimeter measurement have been accounted such as orbital errors, instrumental errors (offset antenna phase center, clock drift electronic time delay), atmospheric errors due to tropospheric and ionospheric effect, time lagging of measurements, clock drift and Doppler shift (Fu and Cazenave, 2001). Other components that can affect the signal such as inverted barometer effect, ocean tides, and electromagnetic bias as shown in Figure 2.

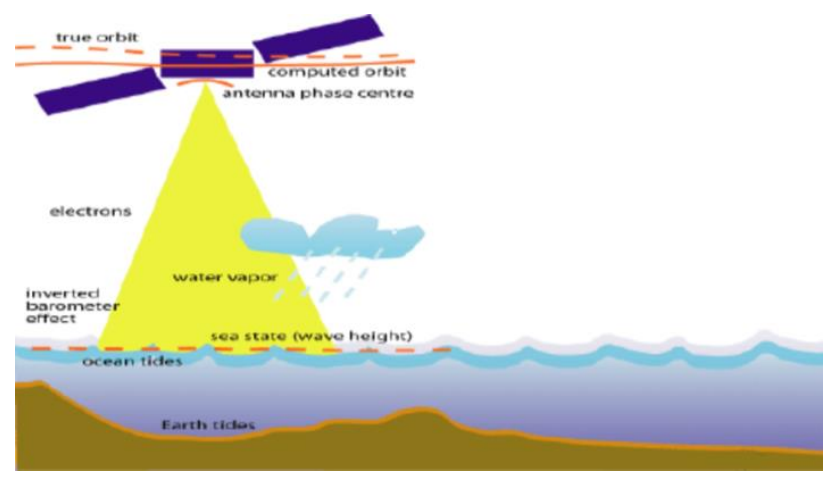

Figure 2. Corrections for altimeter range measurements

Corrected range ( $R_{\text {corrected }}$ ) is related to the Observed range $\left(R_{\text {ob̆ }}\right)$.

$R_{\text {corrected }}=R_{\text {obg }}-\Delta R_{\text {dryy }}-\Delta R_{\text {Wret }}-\Delta R_{\text {iono }}-\Delta R_{\text {geb }}$

$B_{\text {obg }}=c t / 2$ is the measured distance from the signal travel time, $t$ and $c$ is the speed of the echo pulse ignoring refraction. where

$\begin{array}{ll}\Delta B_{\text {dry }} & : \text { Dry tropospheric correction } \\ \Delta R_{\text {nvet }} & : \text { Wet tropospheric correction } \\ \Delta R_{\text {tono }} & : \text { Ionospheric correction } \\ \Delta R_{\text {gsb }} & : \text { Sea-state bias correction }\end{array}$

Altimetry measurement uses a nadir-pointing principle to calculate accurately the time taken of the emitted and returned signal of satellite altimeter. Figure 3 represents the diagram for the altimetry principles. $\boldsymbol{R}$, is the measurement of slant from the angle, $\boldsymbol{\theta}$, where $\boldsymbol{\theta}$ is the antenna pointing angle, and $\boldsymbol{\theta}$ ' is the incidence angle, while $A_{f}$, is the the antenna footprint area (D.B. Chelton et al., 2001). Based on theory, with a specific energy the microwave pulse is permanently transmit from the on-board radar altimeter to the sea surface. The emitted signal from the satellite altimeter towards the sea surface will be reflected back to the altimeter sensor for the accurate measurement of the time taken of the signal between the satellite altimeter and ocean surface.

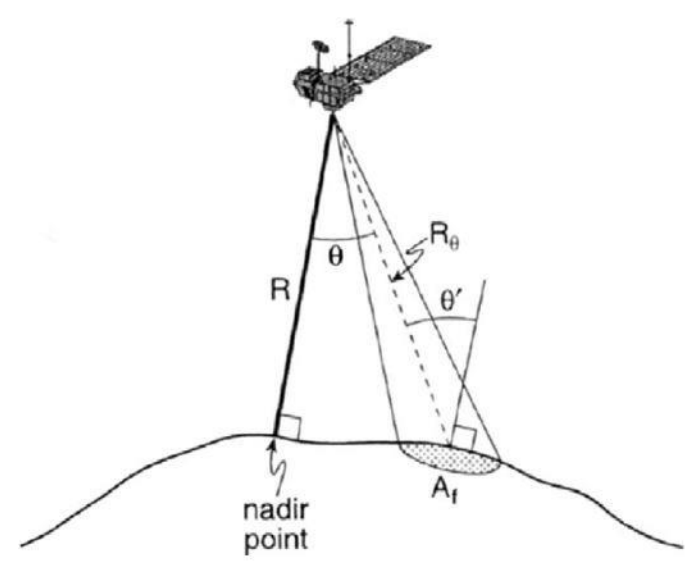

Figure 3. Altimetry principles

\subsection{Buoy Concept}

Buoy is one of the methods used for a meteorological and marine study. Nowadays, many countries in the world has moored and deployed the buoy on the surface of the ocean for meteorological study. Recently, United States of America already moored lots of buoys to form a buoy network that covering most of the west side of the USA coast, several Hawaiian Islands and the Gulf of Mexico (Mathisen, 2010). The used of marine buoy is to measure and collect the meteorological information such as ocean current, wave height, wind speed, humidity, temperature and the ocean $\mathrm{pH}$. The measurement of these ocean parameters from the modern buoy because of the installation of the multipurpose sensors such as wind sensor, air pressure sensor, air temperature sensor, ocean temperature sensor, humidity sensor and others. The modern buoy also equipped with a GPS system in order to give coordinate of the buoy.

\subsection{Previous Research}

There were many research conducted with significant to study the reliability of wind speed measurement using the multimission satellite altimeter for the purpose of providing information to the renewable energy especially in wind turbine energy. Most of the previous study is carried out by assessing the observation of wind speed data from the satellite altimeter and buoy as shown in Table 1. Comparison of data from both 
techniques is conducted and analysed in order to verify the reliability of wind speed data from the satellite altimeter. Several methods of study are approached such as along-track analysis, cross-track analysis and statistical analysis to verify the reliability of wind speed data from multi-mission satellite altimeter.

\begin{tabular}{ccccc}
\hline $\begin{array}{c}\text { Previous } \\
\text { Research }\end{array}$ & $\begin{array}{c}\text { RMSE } \\
(\mathbf{m} / \mathbf{s})\end{array}$ & $\begin{array}{c}\text { Correlati } \\
\text { on }\end{array}$ & $\begin{array}{c}\text { Error } \\
\text { biased }\end{array}$ & Sat \\
\hline $\begin{array}{c}\text { Ebuchi and } \\
\text { Kawamura } \\
(1994)\end{array}$ & 1.99 & $\mathrm{NA}$ & 0.56 & $\mathrm{tx}$ \\
\hline $\begin{array}{c}\text { Hwang } \text { et } \text { al., } \\
(\mathbf{1 9 9 8})\end{array}$ & 1.20 & 0.96 & $\mathrm{NA}$ & $\mathrm{tx}$ \\
\hline $\begin{array}{c}\text { Kshatriya } \text { et } \\
\text { al., (2002) }\end{array}$ & 1.60 & 0.53 & $\mathrm{NA}$ & $\mathrm{tx} / \mathrm{pn}$ \\
\hline $\begin{array}{c}\text { Abdalla } \text { et } \\
\text { al., (2014) }\end{array}$ & 1.50 & 0.91 & -0.20 & $\mathrm{j} 2$ \\
\hline $\begin{array}{c}\text { Adballa } \\
(\mathbf{2 0 1 4})\end{array}$ & 1.48 & 0.86 & -0.32 & $\mathrm{sa}$ \\
\hline $\begin{array}{c}\text { Kumar } \text { et al., } \\
(\mathbf{2 0 1 5})\end{array}$ & 1.13 & 0.91 & -0.28 & $\mathrm{sa}$ \\
\hline
\end{tabular}

Table 1. Previous research findings of the comparisons between altimeter and buoy measurements

Regarding to the previous research above, this paper will present the reliability of wind speed data by using multi-mission satellite altimeter for wind energy over Malaysian seas. Thus, this paper is focusing on the assessment of wind speed climatology and its reliability to support wind energy in Malaysia. The assessment is covered the Malaysian seas with two locations of moored buoy as shown in Figure 1. The altimetry data used were in the range of 24 years period of data starting from January 1993 until December 2016 by using nine different satellite altimeters which are ERS 1, ERS 2, SARAL, ENVISAT 1, CRYOSAT, TOPEX/POSEIDON, JASON 1, JASON 2 and JASON 3. Assessment of this study is done by verifying the altimeter with the ground-truth buoy by using cross-track analysis, statistical analysis and graphical presentation. A set of climatology data also analyzed in order to identify the potential location for wind energy implementation in Malaysia region

\section{RESEARCH APPROACH}

\subsection{Research Approach}

Recently, many researchers conducting their research by using the advance technology as a tool for data acquisition, processing or even data analysis. For marine and oceanographic study, satellite altimeter become one of the elevate technique used to provide a set of data for scientific research. Since 1970s, the launched of satellite altimeter has triggered the oceanographic community to use the altimetry data for marine studies and its advantage by providing good spatial and temporal observations (Fu and Cazenave, 2001). The evolution in space-based data observation such as altimeters has brought the wind speed measurement with a good accuracy comparable with the in-situ observations such as buoy (Dobson et al., 1987).

Wind speed data is retrieved from the satellite altimeter and selected moored buoy. For satellite altimeter, the data extraction divided into two phases; multi-mission satellite altimeter and single mission satellite altimeter. Wind speed data from selected moored buoy that located at Sarawak and Sabah sea, is provided from oil and gas company. Buoy measurement only provide ocean information for particular area of interest due to limited spatial and temporal coverage (Wan et al., 2010). Other than that, these ground-truth buoy measurements are always been used as a benchmark to verify the ocean wind speed observations from the satellite altimeter.

Thus, the wind speed data from the satellite altimeter and buoy are compared to perform data validation and to provide a good continuity contemplate of wind speed data observation (Kumar et al., 2015). Satellite altimeter is an alternative way in providing a precise and stable data with a good coverage of both spatial and temporal. Fairly, many studies have been done in order to assess and validate the reliability of wind speed measurement from the satellite altimeter. Thus, this study is focusing on the reliability of the satellite altimeter for the appraisal of wind turbine energy in Malaysia.

\subsection{Radar Altimeter Database System (RADS) Framework}

Recently, altimetry data has been allocated through international agencies such as National Oceanic and Atmospheric Administration (NOAA) USA, AVISO, and EUMETSAT. RADS is a software produced by the collaborating between Delft Institute for Earth-Oriented Space Research (DEOS) and National Oceanic and Atmospheric Administration (NOAA). It is developed with integrated, approved and calibrated sea-level directory from the multimission altimeter. RADS is established to help in marine and oceanographic research by providing ocean information gathered from the satellite altimeter. RADS is operated using the scheme of an internet facility known as Netherlands Earth Observation NETwork (NEONET) to provide and support a remote sensing observation data. For this part, a special script is used in RADS software to extract a desired wind speed data from satellite altimeter.

The advantages of RADS is, users are able to access, process and verified their own altimetry data with accurate database and precise parameters (Andersen and Schrarroo, 2011). Currently, RADS capacitate all users to avulse data from several satellite altimeters such as ERS 1, ERS 2, JASON 1, JASON 2, ENVISAT 1, TOPEX, POSEIDON, GEOSAT and others. Table 2 shows the current status of satellite altimeter data from Radar Altimeter Database System (RADS).

\begin{tabular}{cccc}
\hline Altimeter & Phase & Time & Cycles \\
\hline ERS 1 & C & 14 Apr 1992 - 20 Dec 1993 & $083-101$ \\
& D & 24 Dec 1993 - 10 Apr 1994 & $103-138$ \\
& E & 10 Apr 1994 - 28 Sep 1994 & $139-140$ \\
& F & 28 Sep 1994 - 21 Mar 1995 & $141-143$ \\
& G & 24 Mar 1995 - 02 Jun 1996 & $144-156$ \\
\hline TOPEX & A & 25 Sep 1992 - 11 Aug 2002 & $001-364$ \\
& B & 10 Sep 2002 - 08 Oct 2005 & $369-481$ \\
\hline POSEIDON & A & O1 Oct 1992 - 12 Jul 2002 & $001-361$ \\
\hline ERS 2 & A & 29 Apr 1995 - 04 Jul 2011 & $000-169$ \\
\hline JASON 1 & A & 15 Jan 2002 - 26 Jan 2009 & $001-260$ \\
& B & 10 Feb 2009 - 03 Mar 2012 & $262-374$ \\
& C & 07 May 2012 - 21 Jun 2013 & $382-425$ \\
\hline ENVISAT1 & B & 14 May 2002 - 22 Oct 2010 & $006-094$ \\
& C & 26 Oct 2010 - 08 Apr 2012 & $095-113$ \\
\hline JASON 2 & A & 04 Jul 2008 - 02 Oct 2016 & $000-303$ \\
& B & 13 Oct 2016 - 04 Dec 2016 & $305-310$ \\
\hline CYROSAT & A & 14 Jul 2010 - 04 Dec 2016 & $004-086$ \\
2 & & & \\
\hline SARAL & A & 14 Mar 2013 - 04 Jul 2016 & $001-035$ \\
& B & 04 Jul 2016 - 04 Dec 2016 & $036-040$ \\
\hline JASON 3 & A & 01 Jan 2016 - 04 Dec 2016 & $000-035$ \\
\hline & Table 2 Status of RADS
\end{tabular}

(Source: http://rads.tudelft.nl/rads/status) 


\subsection{Methodology}

The methodology for this research is involved convergence of satellite altimeter wind speed data with verification from two ground-truth buoys following with statistical analysis and graphical presentation to assess altimeter products with reference of ground-truth buoy. Numerous previous study had applied ground-truth buoy measurement to correlate and verify the satellite altimeter data considering buoy observations as reference data for wind speed study (Queffeulou, 2004). For spatial-temporal analysis of satellite altimeter and buoy observations, a track analysis of satellite altimeter corresponds to ground-truth buoy is approached. The altimeter measurement of spatial-temporal is using 9 days of moving-window, with resolution of $0.25^{\circ} \times 0.25^{\circ}$. Next, the collocated data sets are considered relative and further analysis is approached using statistical analysis by applying the correlation between both measurements and the root mean square error (rmse) calculation (Kumar et al., 2015). This procedure is applied the statistical regression to attain the probable relationship between the ground-truth buoy and the satellite altimeter measurements. This approach is useful to verify the reliability of the wind speed measurement from satellite altimeter correspond with buoys as a bench-mark. The graphical presentation is approached by production of time-series graph for both methods which is necessarily to evaluate the wind speed pattern for both measurements. Other than that, further climatology analysis of wind speed is approached to examine the seasonal effect towards the wind speed observations in Malaysian seas. The advantages of this analysis is to determine the pattern of the wind speed in Malaysian seas region and proposed the potential location for wind energy by selecting a specific place that received high average of wind speed corresponding with seasonal period.

\subsection{Area of Interest and Wind Speed Data}

This paper is conducted in order to provide and assess the wind speed data over Malaysian Sea as shown in Figure.1. The selected area of interest is covered the Malaysian Exclusive Economic Zone (EEZ). There are four zones of Malaysian seas that have been selected to assess the potential offshores/near offshores locations that possesses with a great wind speed. Every year, most of the zones faced with a great wind speed during the Northeast Monsoon (November to February) compare to the other monsoons.

\subsubsection{Altimetry Data}

For multi-mission satellite altimeter, the data extraction is from nine different types of satellite altimeter using Radar Altimeter Database System (RADS). For multi-mission satellite altimeter analysis, the data extraction is corresponded within the study area which is covered the Malaysian seas as shown in Figure. 1. A 24 years period of wind speed data is extracted starting from $1^{\text {st }}$ January 1993 until $31^{\text {st }}$ December 2016. The significant of these multi-mission satellite altimeter measurement, is to conduct a wind speed climatology assessment based on the daily and monthly solutions. Inside this processing, user will define the study area or geographical region in latitude and longitude also the related parameters. For this study, the satellite altimeter data is extracted between $0^{\circ} \mathrm{N}$ to $14^{\circ} \mathrm{N}$ for latitude and $95^{\circ} \mathrm{E}$ to $125^{\circ} \mathrm{E}$ longitude, which covers the four zones of Malaysian seas.
Next, is the single-mission satellite altimeter processing with significant to analyse the along-track of the satellite altimeter over the moored buoys and valuate the spatial coverage of the satellite altimeter. In this single-mission processing, the extraction of wind speed data from the satellite altimeter is based on the observation period from the ground-truth buoy. This study is used ground-truth buoys data from $1^{\text {st }}$ October 1995 until $31^{\text {st }}$ January 2012. Thus, a data selection of cycle and phase for each single-mission satellite altimeter will be referred to the ground-truth buoy period of time. After the selection, several satellite altimeter missions are chosen as shown in Table 3. These seven satellite altimeters are selected based on the time interval of the ground-truth buoys.

\begin{tabular}{lll}
\hline Satellite & Phase & Cycle \\
\hline ENVISAT 1 & B & $006-094$ \\
& C & $095-111$ \\
\hline ERS 1 & G & $150-156$ \\
\hline ERS 2 & A & $004-169$ \\
\hline JASON 1 & A & $001-260$ \\
& B & $262-371$ \\
\hline JASON 2 & A & $000-159$ \\
\hline POSEIDON & A & $113-361$ \\
\hline TOPEX & A & $112-364$ \\
& B & $369-481$ \\
\hline
\end{tabular}

Table 3. Single-mission satellite altimeter selected data from $1^{\text {st }}$ October1995 until $31^{\text {st }}$ January 2012

\subsubsection{Buoy Data}

In this research, wind speed data from the in-situ buoy (groundtruth), are used as a reference/benchmark for the data comparison and assessment with the satellite altimeter. Malaysia has deployed several numbers of buoys at the specific locations over Malaysian seas. For this study, the wind speed data from buoys located at Sabah and Sarawak sea are provided by the oil and gas company. Both of these buoys are installed with the sensors to provide oceanographic information. The buoys were install with the several sensors such as wave sensor, wind sensor, temperature sensor, air pressure sensor and ocean current sensor. For this part, we are used two moored buoy as a bench-mark as shown in Table 4.

\begin{tabular}{llll}
\hline Buoy & Latitude & Longitude & Period \\
\hline Sabah & $5.83 \mathrm{~N}$ & $114.39 \mathrm{E}$ & Nov 04-Dec 07 \\
\hline Sarawak & $5.15 \mathrm{~N}$ & $111.82 \mathrm{E}$ & Oct 95-Jan 12 \\
\hline \multicolumn{4}{c}{ Table 4. Buoy information }
\end{tabular}

\section{RESULTS AND DISCUSSION}

Wind speed measurements that derived from the multi-mission satellite altimeter is distinguished with the ground-truth buoy data to analyze the reliability of satellite altimeter wind speed data. In-situ measurements such as buoy have become a source of continuous measurements of oceanographic information at permanent points. Generally, in-situ measurements always become a bench-mark for the affirmation of the measurements from the satellite altimeter (Kumar et al., 2015). With the improvising of satellite altimeters, the respective blunder for the satellite altimeter has been downsized if compared with the ground-truth buoy, thus the linear-regression method is used for inter-comparison purposes (Durrant et al., 1987). Based on the previous study has concluded the relative error between the satellite altimeter and the ground-truth buoy are relatively equal 
(Caires and Sterl, 2003). The Ground-truth buoy can be used as a bench-mark for quality control upon the instrument errors and for the affirmation part (Zhoa el al., 2012).

\subsection{Validation of Wind Speed Data from Satellite Altimeter and Ground-truth Buoy}

Previous research found that, the accuracy of the satellite altimeter measurements is commensurate with the measurements of the ground-truth buoy. Nowadays, satellite altimeter can provide a persistent and accurate wind speed measurements in a large coverage of both temporal and spatial. Previous study has concluded that the satellite altimeter measurements showing a good significant accuracy with the buoy measurements.

A collocation method for both techniques is used in order to assess and validate the reliability of the measurements from the satellite altimeter. A temporal and spatial assessment of the satellite altimeter is based on the specific parameters of each selected single-mission satellite altimeter as shown in Table 5.

\begin{tabular}{cccc}
\hline Satellite & $\begin{array}{c}\text { Altitude } \\
\mathbf{( k m )}\end{array}$ & $\begin{array}{c}\text { Track spacing } \\
\text { equator }(\mathbf{k m})\end{array}$ & $\begin{array}{c}\text { Repeat } \\
\text { period (days) }\end{array}$ \\
\hline ENVISAT-1 & 796 & 80 & 35 \\
\hline ERS-1 & 780 & 80 & 35 \\
\hline ERS-2 & 785 & 80 & 35 \\
\hline Jason-1 & 1336 & 315 & 10 \\
\hline Jason-2 & 1336 & 315 & 10 \\
\hline TOPEX & 1340 & 315 & 10 \\
\hline CryoSat-2 & 717 & 75 & 28 \\
\hline Saral & 800 & 75 & 35 \\
\hline
\end{tabular}

Table 5. Satellite Altimeter Mission Parameters

\subsection{Data Verification}

Altimeter wind speed is measured from the energy of the reflected signal from the ocean surface roughness (Kumar et al., 2015). The comparison of monthly averages between collocated wind speed from the satellite altimeter and buoys are shown by using the graphical and statistical assessment. Based on Figure 4 and 5 showing that, the graphs of buoy-altimeter versus time to indicate the pattern of the wind speed observation for satellite altimeter and moored buoys at Sabah and Sarawak Sea, respectively.

Based on the Figure. 4, it illustrated a time-series graph by presenting a comparison between collocated satellite altimeter and buoy at point located at Sabah Sea. The graph shows, the wind speed pattern for collocated altimeter and buoy with respect to time is approximately the same. But there is a biased for each point of the pattern. In January 2005, the wind speed value for buoy is $6.17 \mathrm{~m} / \mathrm{s}$ while the satellite altimeter with 7.07 m/s. From December 2005 until April 2006, the pattern of both lines is approximately equal and also happened for the lines pattern from June 2006 until May 2007. As we can see the value of the wind speed from satellite altimeter on July 2007 is higher compared to the buoy with $5.32 \mathrm{~m} / \mathrm{s}$ for satellite altimeter and $3.75 \mathrm{~m} / \mathrm{s}$ for buoy. Apart from that, most of the time these graph illustrated the satellite altimeter has indicated a higher value of wind speed observations compared to the moored buoy. As calculated before, the error biased for this Figure. 4 is positive $0.28 \mathrm{~m} / \mathrm{s}$ accounted with the average difference of the wind speed value from the satellite altimeter and the moored buoy. It means that, the wind speed value from the satellite altimeter is higher compared to the wind speed measurement from the ground-truth buoy.

For Figure. 5, the graph illustrated the comparison of the wind speed pattern between the satellite altimeter and the buoy. As we can see, the wind speed value from both of the measurements showing the same pattern for a certain time during October 1995 until July 1996 and from October 1998 until October 1999. But, at a certain time there were large differences of the wind speed observation for both of the methods; such as for wind speed in December 1996 the satellite altimeter wind speed was $7.15 \mathrm{~m} / \mathrm{s}$ while buoy was $3.81 \mathrm{~m} / \mathrm{s}$. It shows a huge difference value of the wind speed measurements between both of the techniques. This phenomenon also happened in September 2005, the monthly mean value of the wind speed from satellite altimeter was $6.87 \mathrm{~m} / \mathrm{s}$ while buoy was $3.22 \mathrm{~m} / \mathrm{s}$. The graph also shows that, there was a data gap for the buoy during August 2001. These data gap is believed will affect the correlation measurements for both altimeter and buoy. The error biased for the wind speed observation from both techniques for point located at Sarawak Sea is $0.75 \mathrm{~m} / \mathrm{s}$, and these value is larger compared to the error biased of wind speed measurements at point located at Sabah Sea, which was $0.28 \mathrm{~m} / \mathrm{s}$.

Overall, these result has shown that the wind speed values from the satellite altimeter of both points were slightly larger compared to the wind speed values from the buoys. This may be due to the overestimation of wind speed from the satellite altimeter at low wind speed region (Lillibridge el al., 2014). This indicates the existence of swells in low wind speed region showing the ocean surface is rough causing to a strong reflected signal and over-estimation of wind speed measurements from the satellite altimeter (Bhownick et al., 2014).

For a further analysis, a statistical assessment on the monthly average for both of the satellite altimeter and buoy has been applied for each ground-truth buoys at Sabah Sea and Sarawak Sea. These statistical analysis is done to obtain a good comprehension of the wind speed between both of the measurements at a certain time for each point. The statistical parameter presented in this analysis is by looking up at the correlation and Root Mean Square Error (RMSE) for both measurements. As recalled from time-series analysis in the Figure 4 and 5, illustrated overall monthly mean of the wind speed from the satellite altimeter were slightly higher compared to wind speed from the buoys indicating the overestimation of the satellite altimeter wind speed. A further statistical analysis is approached to indicate the performance of the satellite altimeter measurements to show its reliability of providing the wind speed data.

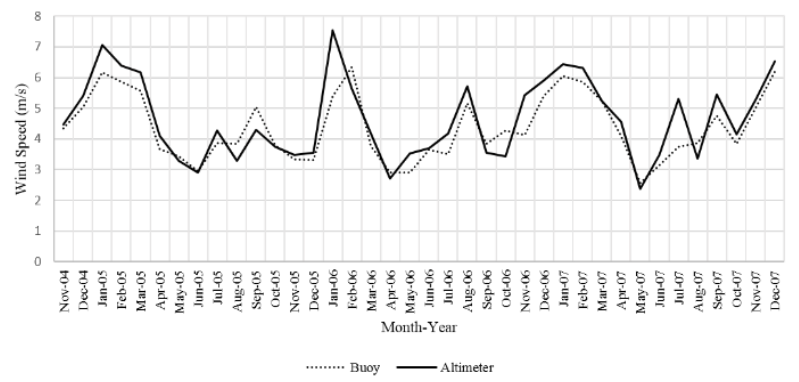

Figure 4. Time-series graph of inter-comparison altimeter and buoy for point located at Sabah Sea for monthly average. 


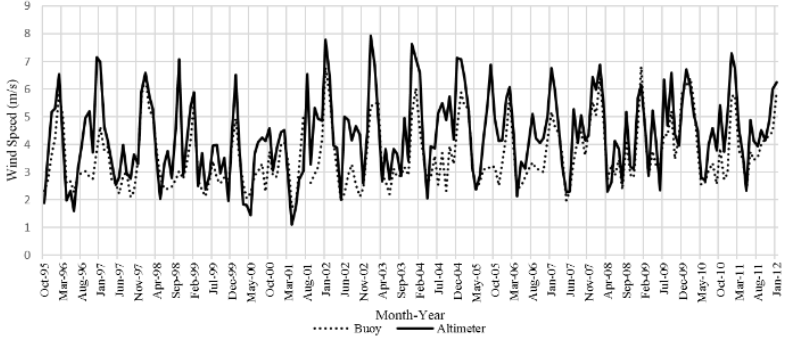

Figure 5. Time-series graph of inter-comparison altimeter and buoy for point located at Sarawak Sea for monthly average.

Based on the Figure 6(a) and (b), represented the correlation graph of the wind speed for point located at Sabah and Sarawak Sea, respectively. These correlation is produced by applying linear regression to both of the wind speed measurements. In Figure 6a), the graph shows the correlation of the wind speed measurements for both methods at Sabah Sea is positive 0.7976 with RMSE value $\pm 0.65 \mathrm{~m} / \mathrm{s}$, while Figure $6 \mathrm{~b}$ ) illustrates the correlation graph for point located at Sarawak Sea is positive 0.6148 and RMSE $\pm 1.25 \mathrm{~m} / \mathrm{s}$. Both of the graphs are shown with a good correlation results, means that the measurement of wind speed between satellite altimeter and buoy are good correlated. However, the RMSE value for point located at Sarawak Sea is much higher with $\pm 1.25 \mathrm{~m} / \mathrm{s}$ compare to RMSE value for point located at Sabah Sea, \pm 0.65 . It can be related with the value of the correlation for both of the graphs, showing Figure 6a) has better positive correlation value compare to Figure 6b). This is happened because of several reasons, previous study explained if the grid point is located away from the coastal buoy, the land influence will affect the grid averaging. Indeed, the closer the satellite tracks to the buoy, the smaller the estimate of the bias between altimeter and the buoy (Shanas et al., 2014). Buoy that located at Sarawak sea is far more away from the land compare to the buoy located at Sabah sea as shown in Figure 7(a) and (b).

(a)

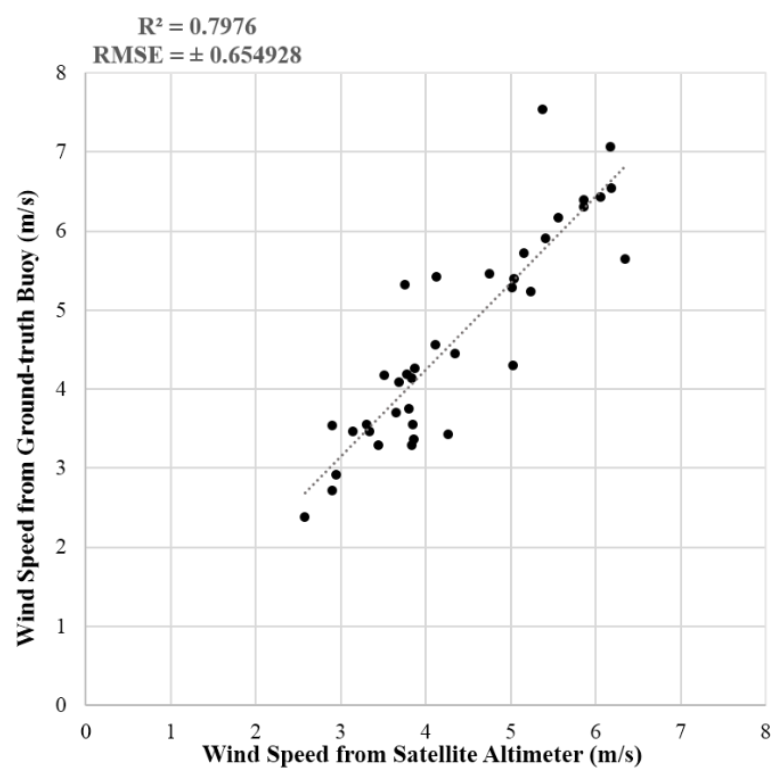

(b)

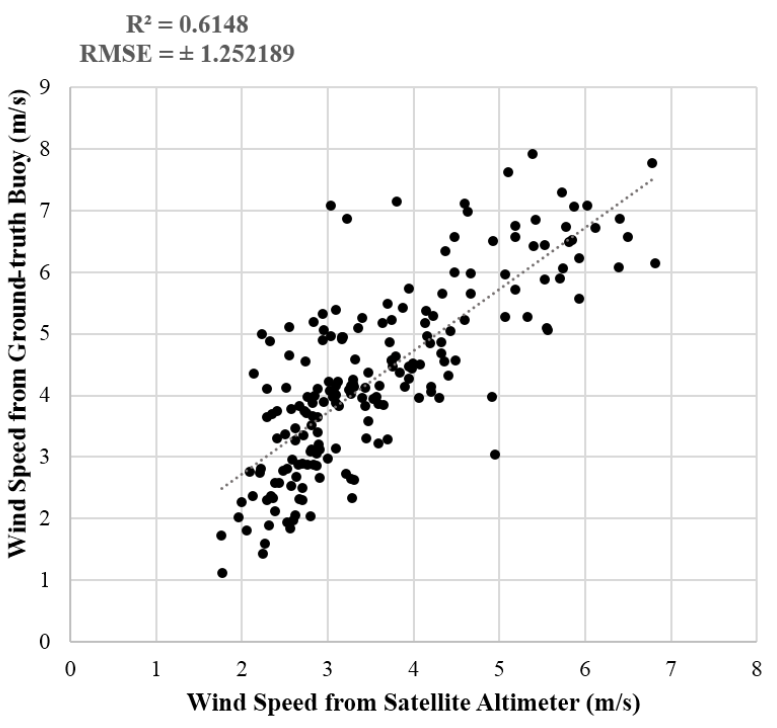

Figure 6. Correlation graph for point located at Sabah Sea (a) and Sarawak Sea (b)

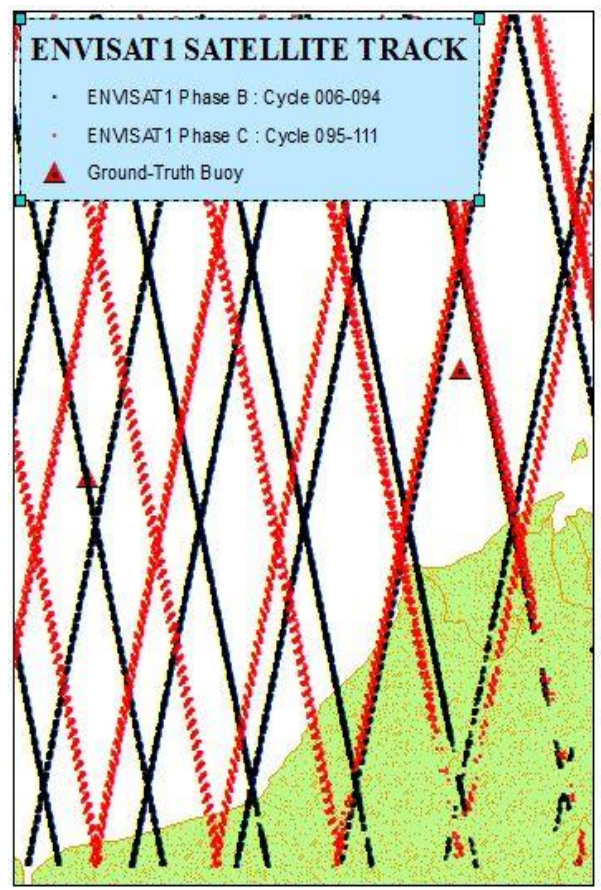

(a) 


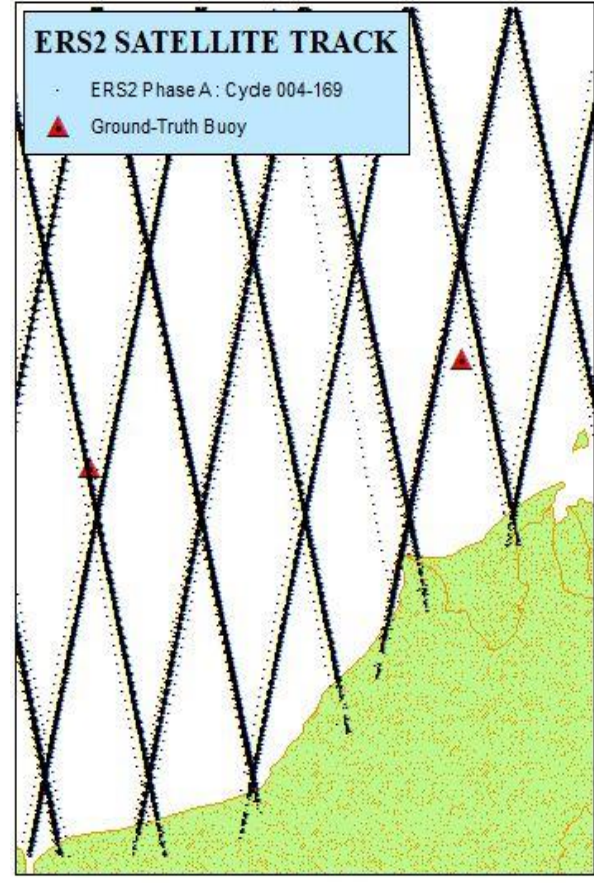

(b)

Figure 7. Satellite track over the ground truth buoy, (a) satellite track from ENVISAT-1 and (b) is satellite track from ERS-2

From the result of the satellite track presented in Figure. 7(a) and (b), has conclude the wind speed correlation and RMSE value for point located at Sarawak Sea should be better compared to the result from point at Sabah Sea. But, a reverse situation occurs explained the correlation and RMSE value for point located at Sabah Sea is much better compared to the point located at Sarawak Sea. This is happened because of the buoy at Sarawak Sea is located at shallow water compare to the buoy at Sabah Sea, where the depth of the water at Sarawak sea is $100 \mathrm{~m}$ while the buoy at Sabah sea is $1032 \mathrm{~m}$. Sarawak point has a shallow water because of the location of the buoy is near with an island. Thus, the presence of land will influence the measurement of wind speed observations from the satellite altimeter. Since, the observation of wind speed from the satellite altimeter is estimated from the backscattered signal from the sea roughness, the shallow water of Sarawak Sea gives effect to the estimation of wind speed for satellite altimeter at Sarawak point. As a result, Sarawak point has a larger value of correlation and RMSE compared to the result with the point at Sabah Sea.

\subsection{Climatology Analysis Due to Seasonal Effects}

This research has utilized the altimetry data from nine satellite missions for 24 years period of observations from year 1993 until 2016. These altimetry data were combined to produce a wind speed climatology data using RADS software. The processing of these climatology data by using RADS is to evaluate the wind speed condition over Malaysian seas correspond with the seasonal variation. The seasonal analysis from climatology data set is based on the average of the monsoon season period which were Northeast Monsoon (November to February), Southwest Monsoon (May to August), First-inter Monsoon (March and April) and Second-inter Monsoon (September and October). The objective of this analysis is to assess the variation of the wind speed climatology data from the satellite altimeter and analyze the condition of the wind speed during each season. Henceforth, to propose a suitable location in Malaysian offshores/near offshores for wind turbine energy is conducted by examined the particular location receiving a strong wind speed at a particular time.

\subsubsection{Northeast Monsoon and Southwest Monsoon}

The low pressure in the continent landmass can caused a seasonal warming phenomenon, which heats up quickly the air above the landmass compare to the air over the ocean (Masserah and Razali, 2016). This phenomenon will cause the monsoon season occurred. Previous research finding showing that, the wind speed during the Northeast Monsoon is stronger than the Southwest Monsoon. During the Northeast Monsoon (November to February), the Australian continent experienced with the summer season brought a low temperature in Asian region and produced a high pressure area compare to the Australian region. Thus, the wind circulates from the high pressure area of Asian continent to the low pressure area of Australian continent. The circulation of the wind across the equator has possess the wind blowing from the east-side of the Peninsular Malaysia are deflected to the Australian continents. During this Northeast Monsoon, wind from South China Sea is blown towards Malaysia region and forming a great wind speed compared to other monsoons (Masserah and Razali, 2016).

Based on the Figure. 8 presents the average of the wind speed during Northeast Monsson (November to February) for 24 years period of time. The map shows the average of the wind speed for the coastal areas is around $4 \mathrm{~m} / \mathrm{s}$ up to $5.7 \mathrm{~m} / \mathrm{s}$. While in Figure. 9, the average of the wind speed during the Southwest Monsoon is range from $2.0 \mathrm{~m} / \mathrm{s}$ up to $4.5 \mathrm{~m} / \mathrm{s}$.

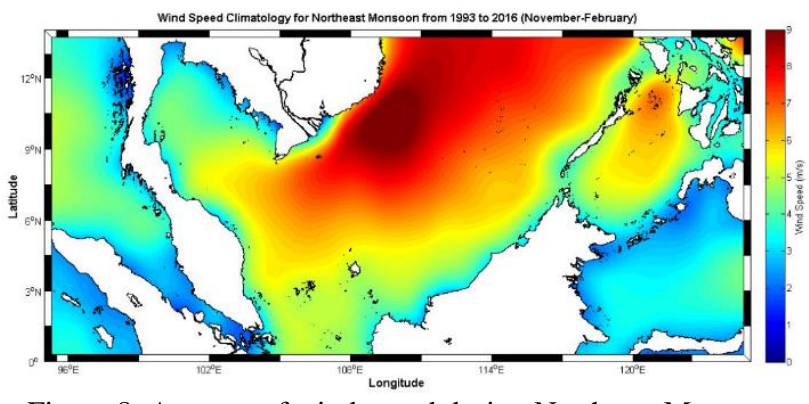

Figure 8. Average of wind speed during Northeast Monsoon from 1993 to 2016

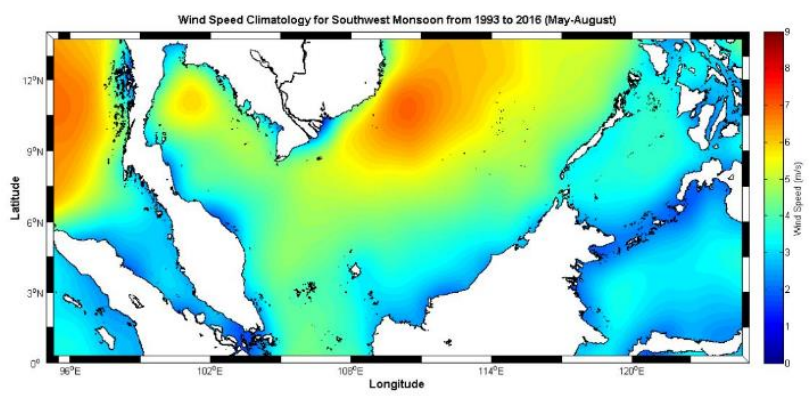

Figure 9. Average of wind speed during Southwest Monsoon 1993 to 2016

\subsubsection{Monsoon Transition}

Malaysia also experienced with two monsoons transition period which are First Inter-Monsoon (March to April) and Second Inter-Monsoon (September to October). These transition monsoons were occurred in short period of time in which the 
wind movement were facing the fluctuation and become slow with value not exceed $5.4 \mathrm{~m} / \mathrm{s}$ (Masserah and Razali, 2016).

During the First Inter-Monsoon in Figure 10, shows the average of the wind speed near the coastal areas is range from $2.0 \mathrm{~m} / \mathrm{s}$ up to $3.5 \mathrm{~m} / \mathrm{s}$. While, Figure 11 represents the wind speed condition during the Second Inter-Monsoon with the average of the wind speed range from $3.0 \mathrm{~m} / \mathrm{s}$ up to $4.0 \mathrm{~m} / \mathrm{s}$. All the graphical result had showing the mean value of the wind speed for the coastal areas were maximum during the Northeast Monsoon up to $5.7 \mathrm{~m} / \mathrm{s}$, and minimum during the transition of the First Inter-Monsoon with the value of the wind speed were $3.5 \mathrm{~m} / \mathrm{s}$. Besides that, all the maps presented South China Sea area is received a stronger wind speed compare to Malacca Straits, Sulu Sea and Celebes Sea.

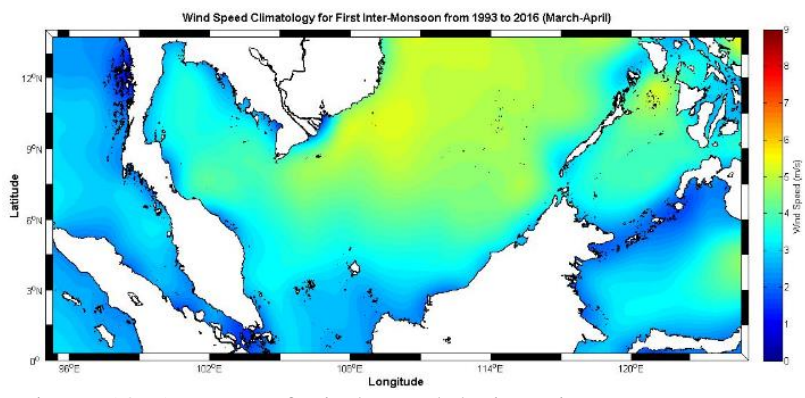

Figure 10. Average of wind speed during First Inter-Monsoon 1993 to 2016

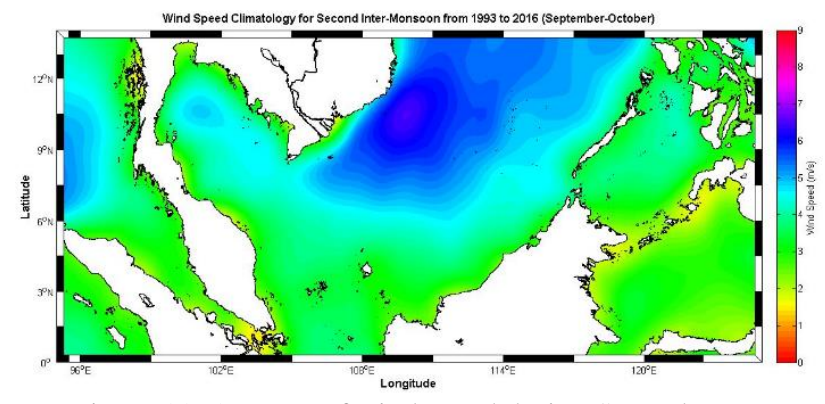

Figure 11. Average of wind speed during Second InterMonsoon 1993 to 2016

\subsection{Wind Speed Climatology Using Time-Series Analysis}

In this part, this paper explained the analysis of the wind speed climatology based on the monthly average of the satellite altimeter wind speed data from 1993 to 2016 . The significant of this analysis is to analyze the wind speed condition for each sea at a particular time.

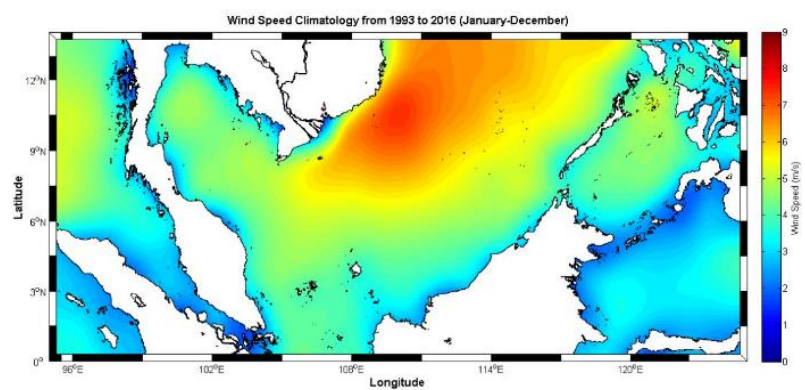

Figure 12. Average wind speed of twelve months for 24 years period 1993 to 2016
Based on Figure 12, the map illustrated the average wind speed for Malaysian seas over 24 years from 1993 until 2016. According to this map, it showed that South China Sea is received a strong wind speed compare to the other seas with maximum value of $7.5 \mathrm{~m} / \mathrm{s}$, followed by Sulu Sea with $5.0 \mathrm{~m} / \mathrm{s}$. While, both of Malacca Straits and Celebes Sea received a low average of wind speed with maximum value of $3.5 \mathrm{~m} / \mathrm{s}$. Based on Figure 13, the monthly assessment of the satellite altimeter wind speed for each Malaysian Seas plotted that South China Sea was dominantly received a strong wind speed, followed by Sulu Sea and two other seas which are Celebes Sea and Malacca Straits. Figure 13 also illustrates each of these Malaysian seas most likely have the same lines pattern of wind speed for each month. Commonly, each part of the sea received a strong wind during the Northeast Monsoon from November to February. South China Sea, Sulu Sea and Celebes Sea experienced a strong wind in January with value $7.5 \mathrm{~m} / \mathrm{s}, 6.1 \mathrm{~m} / \mathrm{s}$ and $3.5 \mathrm{~m} / \mathrm{s}$, respectively. While, Malacca Straits experienced a maximum wind speed in December with $3.3 \mathrm{~m} / \mathrm{s}$.

During the transition monsoons on March to April and September to October, each of the sea experienced with a fluctuated wind direction causing a slow wind speed at that time (Masserah and Razali, 2016). In the first transition monsoon, most of the seas facing with the slowest wind movement starting from March until the end of the April. Due to the location of Malacca Straits surrounded by a land mass especially the Sumatra Island make Malacca Straits received the worst wind speed in April with $2.4 \mathrm{~m} / \mathrm{s}$. Even though, there was a slow movement of wind during this first transition monsoon but South China Sea still receive a strong wind speed compared to the other sea with $3.5 \mathrm{~m} / \mathrm{s}$ as shown Figure 13 .

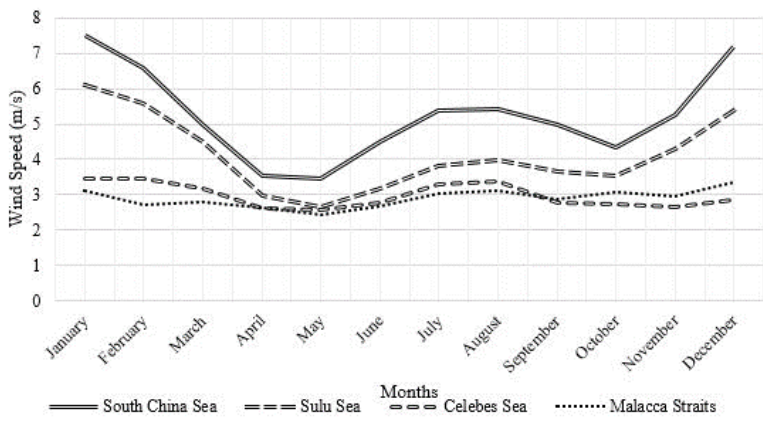

Figure 13. Monthly climatology of wind speed for each Malaysian seas over 24 years

The fluctuated wind movement also happened during the Second Inter-Monsoon (September to October) where all of the four seas facing with slow movement of wind speed. During that time, South China Sea only received maximum $4.9 \mathrm{~m} / \mathrm{s}$ of wind speed in September, while Sulu Sea and Celebes Sea only experienced maximum wind speed with value $3.7 \mathrm{~m} / \mathrm{s}$ and 2.8 $\mathrm{m} / \mathrm{s}$, respectively. In September, Malacca Straits received a minimum wind speed with $2.9 \mathrm{~m} / \mathrm{s}$ and maximum wind speed with $3.1 \mathrm{~m} / \mathrm{s}$ in October. According to the graph in Figure 13, shows the condition of wind speed during the second transition monsoon is slightly higher compare to the first transition monsoon. This is because, during October the wind-blown from the high pressure of Asia continent and the wind that blown towards South China Sea were start to move in the east direction towards the low pressure of Australian continent. In a result, forming a strong wind speed during Northeast Monsoon from November until February. 
Figure 14 presents the graphical average of the wind speed for each months over 24 years of satellite altimeter measurements. According to the graph, the average wind speed is higher in January during the Northeast Monsoon with value $4.7 \mathrm{~m} / \mathrm{s}$ and lower in April during the First Inter-Monsoon with value 2.6 $\mathrm{m} / \mathrm{s}$. Hence, it can be concluded that Malaysia will received a strong wind speed for four consecutive months from November until January with maximum value $4.7 \mathrm{~m} / \mathrm{s}$ and minimum value $4.5 \mathrm{~m} / \mathrm{s}$.

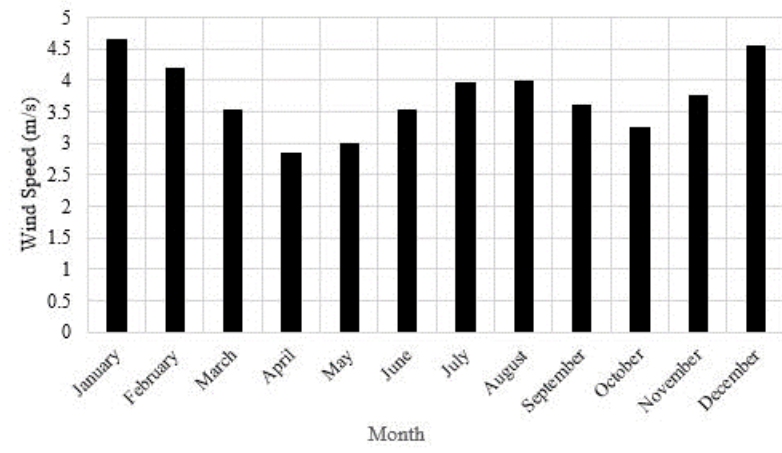

Figure 14. Average wind speed for each month over 24 years (1993-2016)

The analysis showed that, each part of the Malaysian Sea was experienced with a strong wind during the Northeast Monsoon and weak during the first transition monsoon. Apart from that, South China Sea becomes the region that received a strong wind speed compared to the other Malaysian Seas.

\subsection{Proposed Location for Wind Turbine Energy}

The location of Malaysia in low wind speed region has brought a great challenge to find the potential location in Malaysia for the implementation of wind energy and figuring the annual potential energy generated correspond to the strength of wind speed of the location (Mohamed et al., 2015). Thus, the climatology analysis gives an advantage in order to propose a suitable location that has good potential for wind turbine energy. Figure 15 shows three potential locations have experienced a strong wind speed during the Northeast Monsoon and received a strong wind blowing from South China Sea which are Tioman Island, Tenggol Island and Layang-layang Island. Tioman and Tenggol Island were located at the coast of East Peninsular Malaysia facing with strong wind from South China Sea with maximum value of wind speed $5.5 \mathrm{~m} / \mathrm{s}$. While Layang-layang Island is one of the island in Sabah Sea facing with maximum wind speed from South China Sea with the value of $4.5 \mathrm{~m} / \mathrm{s}$.

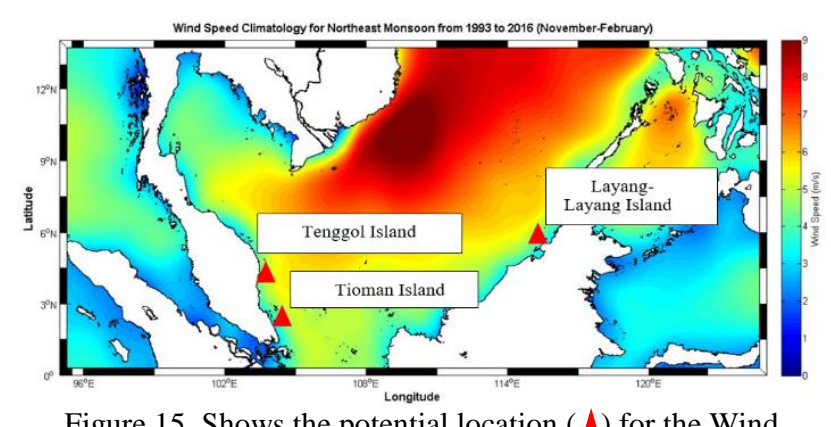

Figure 15. Shows the potential location $(\boldsymbol{\Lambda})$ for the Wind Turbine Generator (WTG)
These selected locations were based on the assessment of the ocean wind speed $10 \mathrm{~m}$ above the sea levels. Since these selected islands facing with a strong wind speed during particular monsoon, the physical height for wind turbine generator need to be considered regarding the maximum value of the receiving wind from the sea towards each of the locations. The positioned of Malaysia in low-wind speed region make the coastal zone of Peninsular Malaysia, Sabah and Sarawak received maximum wind speed value below $7 \mathrm{~m} / \mathrm{s}$ with maximum annual wind power less than $400 \mathrm{~W} / \mathrm{m}^{2}$ as shown in Table 7.

\begin{tabular}{|c|c|c|c|c|c|c|}
\hline \multirow{2}{*}{$\begin{array}{c}\text { Wind } \\
\text { Class }\end{array}$} & \multicolumn{2}{|c|}{$\mathbf{1 0 m}$} & \multicolumn{2}{c|}{$80 m$} & \multicolumn{2}{c|}{$100 m$} \\
\cline { 2 - 7 } & $\begin{array}{c}\text { Density } \\
\left(\mathrm{W} / \mathrm{m}^{2}\right)\end{array}$ & $\begin{array}{c}\text { Wind } \\
\text { Speed } \\
(\mathrm{m} / \mathrm{s})\end{array}$ & $\begin{array}{c}\text { Density } \\
\left(\mathrm{W} / \mathrm{m}^{2}\right)\end{array}$ & $\begin{array}{c}\text { Wind } \\
\text { Speed } \\
(\mathrm{m} / \mathrm{s})\end{array}$ & $\begin{array}{c}\text { Density } \\
\left(\mathrm{W} / \mathrm{m}^{2}\right)\end{array}$ & $\begin{array}{c}\text { Wind } \\
\text { Spee } \\
\mathrm{d} \\
(\mathrm{m} / \mathrm{s})\end{array}$ \\
\hline $\mathbf{1}$ & $<100$ & $<4.4$ & $<240$ & $<5.9$ & $<260$ & $<6.1$ \\
\hline $\mathbf{2}$ & $100-150$ & $4.4-$ & $240-380$ & $5.9-$ & $260-420$ & $6.1-$ \\
& & 5.1 & & 6.9 & & 7.1 \\
\hline $\mathbf{3}$ & $150-200$ & $5.1-$ & $380-490$ & $6.9-$ & $420-560$ & $7.1-$ \\
& & 5.6 & & 7.5 & & 7.8 \\
\hline $\mathbf{4}$ & $200-250$ & $5.6-$ & $490-620$ & $7.5-$ & $560-670$ & $7.8-$ \\
& & 6.0 & & 8.1 & & 8.3 \\
\hline $\mathbf{5}$ & $250-300$ & $6.0-$ & $620-740$ & $8.1-$ & $670-820$ & $8.3-$ \\
& & 6.4 & & 8.6 & & 8.9 \\
\hline $\mathbf{6}$ & $300-400$ & $6.4-$ & $740-970$ & $8.6-$ & $820-$ & $8.9-$ \\
& & 7.0 & & 9.4 & 1060 & 9.7 \\
\hline $\mathbf{7}$ & $>400$ & $>7.0$ & $>970$ & $>9.4$ & $>1060$ & $>9.7$ \\
\hline
\end{tabular}

Table 7. Wind classification (Oh et al., 2010)

\section{CONCLUSION}

In this study, the wind speed data from both satellite altimeter and buoy are compared for each point located at Sabah and Sarawak Sea. The study of 24 years wind speed data has proven its reliability to support the wind energy in Malaysia offshores. The result has demonstrated that the wind speed from the satellite altimeter are compared well with the ground-truth buoy and have a positive correlation for both points at Sabah and Sarawak sea with 0.7976 and 0.6148 respectively. Monthly mean statistics shows that the RMSE value for the satellite altimeter and buoy at Sabah Sea is $\pm 0.65 \mathrm{~m} / \mathrm{s}$, while for point located at Sarawak Sea with RMSE $\pm 1.25 \mathrm{~m} / \mathrm{s}$. The RMSE value is reasonable if compared with the previous study of collocated satellite altimeter and buoy as shown in Table 1.

The climatology wind speed data analysis shows that Northeast Monsoon received stronger wind speed from November until February with maximum value of $5.7 \mathrm{~m} / \mathrm{s}$. This is because of the circulation of ocean wind between two continents from low pressure to high pressure as mentioned in sub-section 3.3.1. During Southwest Monsoon, Malaysian Seas experienced a maximum wind speed with $4.5 \mathrm{~m} / \mathrm{s}$. Occasionally, due to the fluctuate movement of the wind in short period of time on First Inter-Monsoon and Second Inter-Monsoon brought a weak wind speed condition for each sea. Overall, Malacca Strait has possessed a week wind speed for each monsoon especially in the Second-Inter Monsoon with value of $2.3 \mathrm{~m} / \mathrm{s}$. From this result, most of the offshore and near coastal island in Malacca Straits were not suitable for wind energy implementation due to weak wind speed condition. Other than that, the location of Malacca Straits on the side of Sumatra Island has blocked the wind movement from the other continent. In reverse, for an offshores and near-coastal island facing the South China Sea have a great potential to provide a strong wind speed for wind energy in Malaysia. Most of the near-coastal Malaysian island 
on South China Sea receive a maximum wind speed of $5 \mathrm{~m} / \mathrm{s}$ and stronger during the Northeast Monsoon with average 5.5 $\mathrm{m} / \mathrm{s}$. On behalf of that, three locations were proposed for wind energy site such as Tenggol Island (Terengganu), Tioman Island (Pahang) and Layang-layang Island (Sabah).

Based on the wind speed assessment, this paper has highlight the measurements of the wind speed data from the satellite altimeter is reliable to provide a useful and reliable wind speed information to support the wind energy in Malaysia for the future implementation of a green renewable energy.

\section{ACKNOWLEDGEMENT}

The authors would like to thank to TU Delft, NOAA, Altimetrics LLC for providing altimetry data through Radar Altimeter Database System (RADS). We are grateful to the Ministry of Education (MOE) Malaysia, Fundamental Research Grant Scheme (Vot number: 4F706) and Universiti Teknologi Malaysia for funding this research under Research University Grant (Vot number: 12H99).

\section{REFERENCES}

Abdul Aziz W.A.W, Omar K. M., Omar Y, Din A.H.M., 2014. Ocean wind speed characteristics over Malaysian Seas from multi-mission satellite altimeter during monsoon period, Jurnal Teknologi (Science \& Engineering), 4(71), pp. 79-82.

Andersen,O., B., Schrarroo, R., 2011. Range and Geophysical Corrections in Coastal Regions: And Implications for Mean Sea Surface Determination. In Coastal Altimetry.

Bhownick et al., 2015. Analysis of SARAL/Altika wind and wave over Indian Ocean and its real-time application in wave forecasting system at ISRO, Mar. Geod, 38(1), pp. 396-408.

Caires, S., Sterl, A., 2003. Validation of ocean wind and wave data using triple collocation, J. Geophys. Res, 108(C3), 3098.

D.B. Chelton, J.C Ries, B.J. Haines, L.L. Fu, P.S. Callahan., 2001. Satellite Altimetry, Int. Geophys.

Dobson et al., 1987. Validation of Geosat altimeter-derived wind speeds and significant wave heights using buoy data. $J$. Geophys, 92(10), 719-731.

Durrant et al., 1987. Validation of Geosat altimeter-derived wind speeds and significant wave heights using buoy data, $J$. Geophys. Res, 92(10), pp. 719-731.

Fu, L., Cazenave., 2001. A Satellite Altimeter and Earth Sciences: A Handbook of Techniques and Application. Academic Press.

J. P. Mathisen., 2010. Metocean data. Meteorological Technology International.

L. W. Ho., 1993. Wind Energy in Malaysia: Past, Present and Future, Renewable and Sustainable Energy Review, 53, pp. 279-295.
Lillibridge, J., Scharoo, R., Abdalla, S., Vandermark, D., 2014. One- and Two-dimensional wind speed models for Ka-Band altimetry, J. Atmos. Ocean Tech, 31, pp. 630-638.

Mohamed Nor, K., M. Shaaban., H. A. Rahman, Feasibility Assessment of Wind Energy Resources inMalaysia Based onNWP Model. Renewable Energy. Elsevier. pp. 147-154, Johor Bahru: Malaysia.

N.K Masserah, A.M. Razali., 2016. Modelling the wind direction behaviors during the monsoon seasons in Peninsular Malaysia, Renewable and Sustainable. Energy Rev., 56, pp. $1419-1430$

P.R Shanas, V.S. Kumar, N.K. Hithin., 2014. Comparison of gridded multi-mission and along-track mono-mission satellite altimetry wave heights with in-situ near-shore buoy data, Ocean Engineering, 83, pp. 24-35.

Queffeulou, O,. 2004. Long Term validation of wave height measurements from altimeters. Mar. Geod, 27, pp. 495-510.

Satellite images (2016, November 20). Retrieved from Google Earth National Oceanic and Atmospheric Administration, U.S NAVY website: https://www.google.com/earth/.

T.H. Oh, S.Y. pang, S.C Chua., 2010. Energy Policy and Alternative Energy in Malaysia: Issues and Challenges for Sustainable Growth. Renewable Sustain Energy Rev, 14, pp. 1241-1252.

U.M Kumar, D. Swain, S.K. Sasamal, N.N Reddy, T. Ramanjappa., 2015. Validation of SARAL/Altika significant wave height and wind speed observations over North Indian Ocean, Journal of Atmospheric and Solar-Terrestrial Physics, 135, pp. 174-180.

W.B Wan Nik, M.Z. Ibrahim, K.B Samo., 2010. Wave Energy Potential of Peninsular Malaysia, ARPN J. Appl Sci, 5, pp. 1123.

Zhoa, D., Li, S., Song, C., 2012. The comparison of altimeter retrieval algorithms of the wind speed and the wave period, Acta Ocean. Sin, 31(3), pp. 1-9. 